\title{
Covered Interest Parity Deviations Between India And The US
}

\author{
Vadhindran K. Rao, Metropolitan State University, Minneapolis, USA
}

\begin{abstract}
Prior studies have tested Covered Interest Parity (CIP) between India and the United States and found substantial deviations. The main objective of the current study is to econometrically model and explain deviations from CIP. Further, the study contributes to the literature by proposing an approach to testing CIP after allowing for country risk. A preliminary analysis suggests that there are two types of shocks that impact the CIP deviation, also referred to as the Covered Interest Differential (CID): permanent shocks and temporary shocks. The permanent shocks may be interpreted as reflecting a change in the country risk premium and the temporary shocks as reflecting transient effects and disequilibrium. The paper uses a bivariate Vector Autoregression (VAR) approach to model the joint dynamics of the CID and the forward premium, and applies the methodology of Blanchard and Quah (1989) to separate the impact of the two types of shocks. Impulse-Response analysis shows that a one standard deviation permanent shock has an immediate, substantial impact on the CID. However, forecast error variance decomposition reveals that less than 30\% of the variability in the CID is caused by such permanent shocks. Further, permanent shocks account for less than 5\% of the forecast error variance of the forward premium, which suggests that covered interest arbitrage activity has limited influence on the forward premium. Temporary shocks appear to be related to transient volatility in the forward premium, and such shocks initially affect both the forward premium and the CID to approximately the same extent. The manner in which the CID responds to a temporary shock suggests considerable impediments to arbitrage. However, the fact that the CID recovers at a slightly faster rate than the forward premium, especially in the initial periods, suggests that capital restrictions are not completely binding.
\end{abstract}

Keywords: Covered Interest Parity; Permanent-Temporary Decomposition; India

\section{INTRODUCTION}

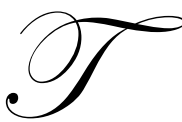

he financial sector in India has undergone substantial liberalization over the last two decades (Jain and Bhanumurthy, 2005 and Prasad, 2009). There have been a number of studies over the years investigating the extent of financial integration of India with global markets. The issue is important as it has implications for monetary and exchange rate policy. As is well known from the Theory of the Impossible Trinity, the greater the degree of financial integration, the more difficult it is for monetary authorities to simultaneously control both interest rates and exchange rates.

While there are many approaches to testing for financial integration (Obstfeld and Taylor, 2004), perhaps the most common approach is to test for Covered Interest Parity (CIP), an equilibrium relationship that links the money markets of two countries through the foreign exchange market. Simply put, CIP states that in the absence of risk differences and market frictions, there should be (approximate) equality between the interest rate differential and the forward premium.

$$
\frac{F-S}{S} \approx r_{d}-r_{f}
$$


Above, $S$ is the spot exchange rate (units of domestic currency per unit of foreign currency), $F$ is the forward rate, $r_{d}$ is the domestic interest rate and $r_{f}$ is the foreign interest rate. The above condition can be equivalently, and more precisely, stated as follows:

$$
1+r_{d}=\frac{1}{S}\left(1+r_{f}\right) F
$$

The Left Hand Side (LHS) of the above equation is the return from investing one unit of the domestic currency in the domestic money market (or the domestic currency's euromoney market). The Right Hand Side (RHS) is the (covered) return from investing one unit of the domestic currency in the money market of the foreign currency with the exchange rate risk covered in the forward market. To spell out the steps of such a transaction, the first term on the RHS represents the conversion of a unit of domestic currency into foreign currency in the spot foreign exchange market, the second term is the return in foreign currency from investing the proceeds and the third term is the equivalent amount in domestic currency from selling the foreign currency return at the forward rate.

The Covered Interest Differential (CID) is the difference between the domestic return and the covered return. Equivalently,

$$
C I D \approx\left(r_{d}-r_{f}\right)-\left(\frac{F-S}{S}\right)
$$

As per CIP, the CID should be zero on the basis of an arbitrage argument. If the domestic return is lower than the covered return, the arbitrage would consist of borrowing the domestic currency and investing in the foreign currency with the foreign exchange risk covered by a short forward contract. On the other hand, if the domestic return is higher, the arbitrage would consist of borrowing in the foreign currency, covering the foreign exchange risk by a long forward contract, and investing in the domestic currency. This argument, of course, can hold perfectly only in the total absence of impediments to arbitrage. In reality, country risk premiums, restrictions on capital flows and other market frictions cause deviations from CIP resulting in a non-zero CID.

In testing for CIP in the context of developed markets, the focus has been on the question, does CIP hold within the bounds set by transactions costs? The literature on this is extensive, and a good source for a review is Sarno and Taylor (2002). An early study was by Frenkel and Levich (1975), who studied euro-deposit rates from the 1960s for the Canadian dollar-US dollar and the British pound-US dollar pairs. They concluded that almost all of any apparent deviations from CIP were due to transactions costs. In a subsequent study, Frenkel and Levich (1981) concluded in favor of CIP holding during the post-Bretton Woods regime of the 1970s as well. Other notable studies over the years include Taylor (1987), Clinton (1988), Frankel (1991), Popper (1993), Takezawa (1995), Balke and Wohar (1997), Obstfeld and Taylor (2004) and Batten and Szilagyi (2006). While there is some controversy about whether CIP held during the 1970s and 1980s, studies based on subsequent periods mostly conclude in favor of CIP. After examining monthly data for the German mark, the British pound and the US dollar over a long period from 1921 through 2003, Obstfeld and Taylor (2004) found that CIP deviations were few and far between in the post1980 period. Using daily data for the US dollar-Japanese yen pair, Batten and Szilagyi (2006) came to a similar conclusion regarding the post-2000 period.

In the Indian context, almost all of the interest has centered on CIP between Indian and US rates. Early studies such as Varma (1997), Bhoi and Dhall (1998) and Mishra, Sebastian and Ramanathan (2001) came out with strong, negative results. More recent studies have found some partial support for CIP. Bhatt and Virmani (2005) estimate a regression of the US Dollar forward premium on the T-bill interest rate differential between India and the US, and are unable to reject CIP. Using regression analysis, Sharma and Mitra (2006) find that the interest rate differential is one of the determinants of the forward premium on the dollar-rupee currency pair. However, based on their finding that other variables such as the current account balance and exchange rate movements also play a significant role in explaining forward premia movements, they conclude that demand and supply for forward contracts arising from hedging and speculative motives play an important role as well. George and Mallik (2009a) 
extend this line of research by investigating and finding support for their hypothesis that central bank actions to smooth interest rates and prices drive a wedge between the forward premium and the interest rate differential. In a related study, George and Mallik (2009b) conclude that current account transactions play a more important role than capital flows in determining forward premia. Another recent study is by Hutchison et al (2009), who hypothesize that there is a no-arbitrage band around the parity due to transactions costs and capital controls. However, if for some reason, the CID were to move outside this band, then arbitrage activity would start to drive the CID back towards the band. Among their objectives are to determine whether the width of the band has narrowed over time and whether the speed of adjustment has increased over time. To that end, they use the Self Exciting Threshold Autoregression (SETAR) methodology to model the CID, and estimate their model using weekly data for different sub-periods over the time span from January 1999 through January 2008. They find that adjustment towards the noarbitrage CIP band is rapid throughout the sample period. The width of the band is smaller in the second and third sub-periods, January 2003 to April 2005 and April 2005 to January 2008, as compared to the first, January 1999 to January 2003. Therefore, they conclude that barriers to arbitrage are lower in the post-2003 period. Buigut and Rao (2011) reexamine covered interest parity using monthly data on Indian swap rates for the period from October 2002 to September 2009. They find little evidence of a cointegrating relationship between the domestic interest rate and the covered interest rate, although there is some indication of a downward trend in the CID during the period before the recent global financial crisis (i.e., prior to June 2007) .

In sum, most of the studies set in the Indian context have found that financial integration with the US is far from complete and that substantial deviations from CIP exist. The main objective of the current study is to model and explain CIP deviations. First, a preliminary analysis is carried out using weekly data on 1 year rates to confirm the existence of CIP deviations. The next question is whether the CID is stationary. As the CID may be viewed as consisting of a country risk premium plus stationary noise, a stationary CID would indicate a stable country risk premium and unchanged capital movement restrictions. However, the data do not support this. The forward premium is stationary, but the CID is found to be integrated of order one, written as I(1), even if one allows for a deterministic trend.

The I(1) nature of the CID implies that the CID is driven by two types of shocks: permanent and temporary. Permanent shocks presumably represent changes in the country risk premium, arising from changes in country risk, risk aversion or capital restrictions. As seen from equation (3), the CID may be viewed as the difference between the interest rate differential and the forward premium. The stationarity of the forward premium indicates that the impact of any permanent shock has a lasting effect only on the interest rate differential. Equation (3) also suggests that temporary shocks may be of two kinds: (i) changes in the forward premium (such as arising from changes in speculative or hedging activity) without an immediate offsetting adjustment in the interest rate differential, and (ii) changes in the interest rate differential (such as from a transient inflation shock) without an immediate offsetting adjustment in the forward premium. Thus, these transient shocks would reflect temporary disequilibrium.

The question arises, what proportion of the variability in the CID is due to permanent shocks and what proportion to transient misalignments? Which of these is the dominant source of movements in the CID? Further, the decomposition into permanent and temporary shocks can shed some light on whether CIP holds in a riskadjusted sense (i.e., after allowing for a country risk premium). Isolating temporary shocks would help in estimating the magnitude of a typical temporary CIP deviation and the speed with which the CID recovers from a temporary shock, with implications for market efficiency.

As is well known, univariate techniques provide no unique way to separate a variable's permanent and temporary components. However, the methodology introduced by Blanchard and Quah (1989) provides a way to accomplish this separation in the framework of a structural Vector Autoregression (VAR). The methodology requires a second variable that is affected by the same two shocks. In this case, the forward premium is a good candidate. Accordingly, the study uses a bivariate Vector Autoregression (VAR) approach to model the joint dynamics of the CID and the forward premium, and applies the methodology of Blanchard and Quah (1989) in a bid to identify the permanent and temporary components of the CID. 
The rest of the paper proceeds as follows. Indian swap rates play an important role in this study. The next section, therefore, provides a brief introduction to the Indian interest rate swap market. The following section describes the data and methodology, and presents results. The last section concludes with a summary of the results and a brief discussion of the study's limitations.

\section{COVERED INTEREST PARITY AND THE SWAP MARKET}

Interest rate swaps were first introduced in India in 1999, and this market has since seen tremendous growth from a weekly volume of around 5 million US dollars in 2001 to over 2 billion in 2009. It is interesting to note that this growth has taken place despite the absence of a well-developed term money market. In fact, as a consequence of this lack, the most widely used floating rate benchmark is the overnight Mumbai Inter-Bank Offer Rate or overnight Mibor. Swaps based on this benchmark rate are traded for a number of maturities ranging from one month to ten years and are termed Overnight Indexed Swaps (OIS) or overnight Mibor swaps. The overnight money market is active and liquid, and consequently overnight Mibor serves as a credible reference rate. Settlement on swaps with a maturity of up to one year takes place at maturity, and on longer term swaps on a six-monthly basis. Another type of swap is based on the Mumbai Interbank Forward Offer Rate or Mifor. This is a reference rate that is perhaps unique to the Indian market. Unlike (say) the six-month Libor (London Interbank Offer Rate), which is the rate at which banks borrow from one another in the London money market, the six-month Mifor is not a rate at which banks directly borrow or lend. Instead, the six-month Mifor fixing is calculated as (approximately) the sum of six month US dollar Libor and the six month dollar/rupee forward premium. The daily Mifor fixings for other standard maturities ranging from one month to one year are carried out similarly and published by Reuters on a daily basis.

For the purpose of this study, the importance of the Mibor swap and Mifor is a consequence of the following. First, note that the Mifor is essentially the covered interest rate. Second, given the lack of a credible, interbank, term market rate, the Mibor swap rate is arguably a decent proxy for rupee borrowing and lending rates. As such, a strong argument can be made for an (approximate) arbitrage relationship between (say) the one year Mibor swap rate and the one year Mifor. If the one year Mifor is lower than the one year Mibor swap rate, then an arbitrageur with access to both rupee and dollar money markets can borrow at Mifor and invest at the Mibor swap rate. Borrowing rupees at Mifor requires the following transactions:

(i) Taking out a dollar loan at Libor

(ii) Selling the dollars for rupees in the spot foreign exchange market

(iii) Entering into a forward contract to buy the amount of dollars needed to pay off the loan at year-end.

The effective interest rate in rupees of this loan is Libor plus the dollar-rupee forward premium. Investing these borrowed rupees at the Mibor swap rate requires the following:

(i) Investing the funds in the overnight rupee money market, and rolling over this investment (including interest) on a daily basis

(ii) Entering into a one-year receive fixed, pay floating Mibor swap (OIS).

The end-of-year proceeds from the rolled-over investment will (more or less) pay for the floating leg of the Mibor swap. Thus, these transactions are (approximately) equivalent to investing at the one-year Mibor swap rate.

Conversely, if the one year Mifor is higher than the one year Mibor swap (OIS) rate, the arbitrageur will borrow at the Mibor swap rate and invest at the Mifor. Borrowing at the Mibor swap rate requires:

(i) Borrowing rupees in the overnight money market, and rolling over the borrowing (including interest) on a daily basis

(ii) Entering into a pay fixed, receive floating one year Mibor swap.

At year-end, the amount received on the floating leg of the swap will (more or less) equal the amount required to be repaid on the rolled-over rupee loan. Investing these borrowed rupees at Mifor requires: 
(i) Converting the funds into dollars at the spot rate

(ii) Investing the dollars at one year Libor

(iii) Entering into a forward contract to sell the year-end proceeds of the dollar investment for rupees.

Thus, arbitrage activity will push the Mibor swap rate and the Mifor towards each other. It may be noted that such arbitrage is not "riskless" because neither the Mibor swap rate nor the Mifor can be exactly locked in by our arbitrageur. Regarding the Mibor swap rate, the problem is due to the likely daily mismatch between the Mibor fixing for the day (on which the swap cash flows are based) and the overnight rate at which the arbitrageur actually borrows or lends funds on that day. Regarding Mifor, the problem is due to the likely mismatch between the Libor and the forward premium used for the Mifor fixing and the actual Libor and forward premium at which the arbitrageur is able to transact. However, it can be argued that the discrepancy in cash flows due to these mismatches is likely to be small due to averaging effects on the deviations over the entire year. A bigger problem is that risk considerations and market imperfections, such as transaction costs and capital restrictions, will drive a wedge between the two rates, and thus cause a non-zero CID.

In light of the above, it would clearly be futile to expect equality between the domestic and covered interest rates in the Indian context. A more realistic question is whether there is a long-term equilibrium relationship between the domestic interest rate (the Mibor swap rate) and the covered interest rate (Mifor). The next section contains more details about the data and methodology. The remaining portion of this section provides a brief overview of the results of the preliminary tests on the data, so as to motivate the main objective of the study.

The study uses weekly time series data of one year Mifor, one year Mibor swap rates and one year dollarrupee forward premium. Preliminary analysis reveals that the Mibor swap rate and Mifor are both I(1) and thus nonstationary; however, the forward premium appears stationary. Given the I(1) nature of Mibor and Mifor, a (weak) test for CIP is whether the two rates are cointegrated. Cointegration tests yield a negative result and indicate that the Covered Interest Differential (CID) is also an I(1) process. As such, the CID should have a permanent component and a temporary component. The next section describes the data and methodology used to separate the two types of shocks and presents the findings.

\section{DATA, METHODOLOGY AND RESULTS}

The study is based on weekly data for the period from January 2004 through September 2009 on the 1 year Mibor swap rate, the 1 year Mifor and the 1 year US dollar/rupee forward premium. The raw data sources are as follows: the Mibor swap rate is from Bloomberg, and the Mifor and forward premium are from Reuters. The raw data were converted into continuously compounded rates. Below are summary statistics for the 1 year Mibor swap rate (which serves as the domestic interest rate), the 1 year Mifor (which is the covered interest rate) and the 1 year US dollar/rupee forward premium. Also included are the summary statistics for the CID, the spread between the domestic and covered interest rates.

Table 1: 1 Year Rates: Summary Statistics (in per cent)

\begin{tabular}{|l|c|c|c|c|}
\hline \multicolumn{1}{|c|}{ Statistics } & Mifor & Mibor swap rate & Forward premium & CID \\
\hline Mean & 5.29 & 5.94 & 1.67 & 0.64 \\
\hline Standard Error & 0.10 & 0.08 & 0.05 & 0.07 \\
\hline Median & 5.08 & 5.70 & 1.52 & 0.35 \\
\hline Standard Deviation & 1.76 & 1.34 & 0.94 & 1.24 \\
\hline Kurtosis & 0.00 & -0.32 & 0.95 & -0.22 \\
\hline Skewness & 0.13 & 0.41 & 0.68 & 0.70 \\
\hline Range & 9.08 & 6.03 & 5.80 & 5.96 \\
\hline Minimum & 1.17 & 3.62 & -0.78 & -1.85 \\
\hline Maximum & 10.26 & 9.66 & 5.02 & 4.12 \\
\hline
\end{tabular}

The sample mean of the 1 year Mibor swap rate (hereafter referred to as Mibor) exceeds that of the 1 year Mifor (hereafter referred to as Mifor) by about 64 basis points (bps). Thus, over the sample period, the CID has been 
positive on average, suggesting that a strategy of borrowing at Libor and investing at Mibor would have been profitable on average, even after covering for exchange rate risk. Of course, such a statement ignores country risk premium and transactions costs. As may be seen in Figure 1, it is interesting to note that while Mifor, for the most part of the sample period, has been lower than the Mibor swap rate, there have been periods in which Mifor has been higher. Another feature apparent from the graph is that the two rates appear to move together to some extent. (However, as mentioned below, cointegration test results do not support the existence of a long-term linear relationship.) It is also interesting to observe that Mifor shows greater variability than Mibor. However, as may be seen in Table 1, Mifor does not show much skewness or kurtosis, whereas Mibor shows positive skewness and negative kurtosis.

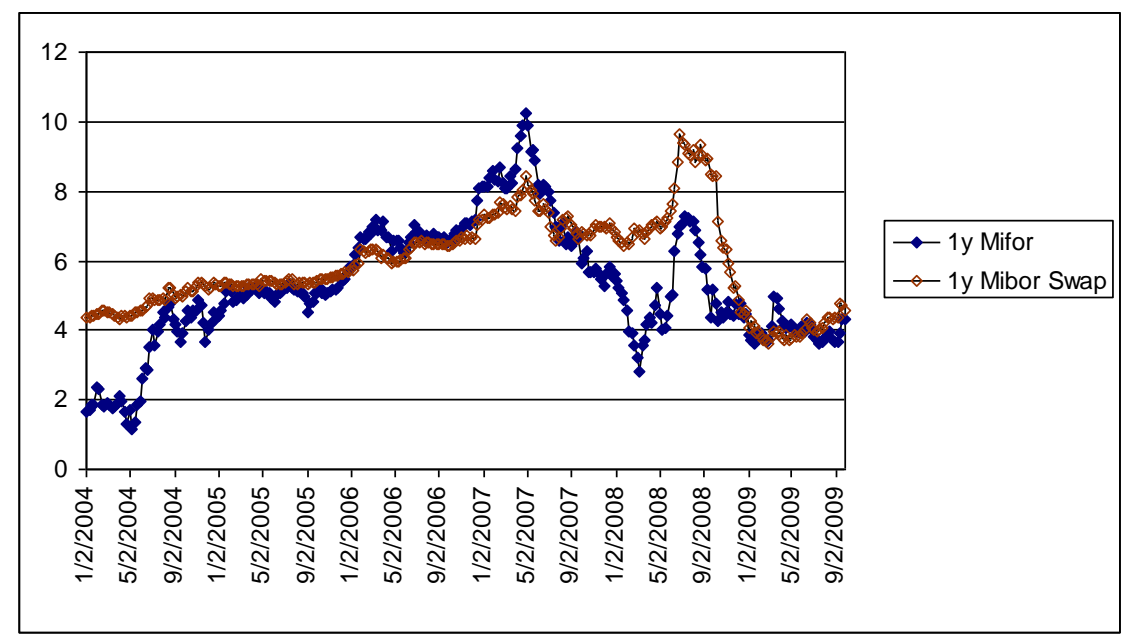

Figure 1: Time Series of Interest Rates (in per cent)

Figure 2 shows the time series of the (negative of the) CID and the forward premium. Some degree of correlation between the two is evident.

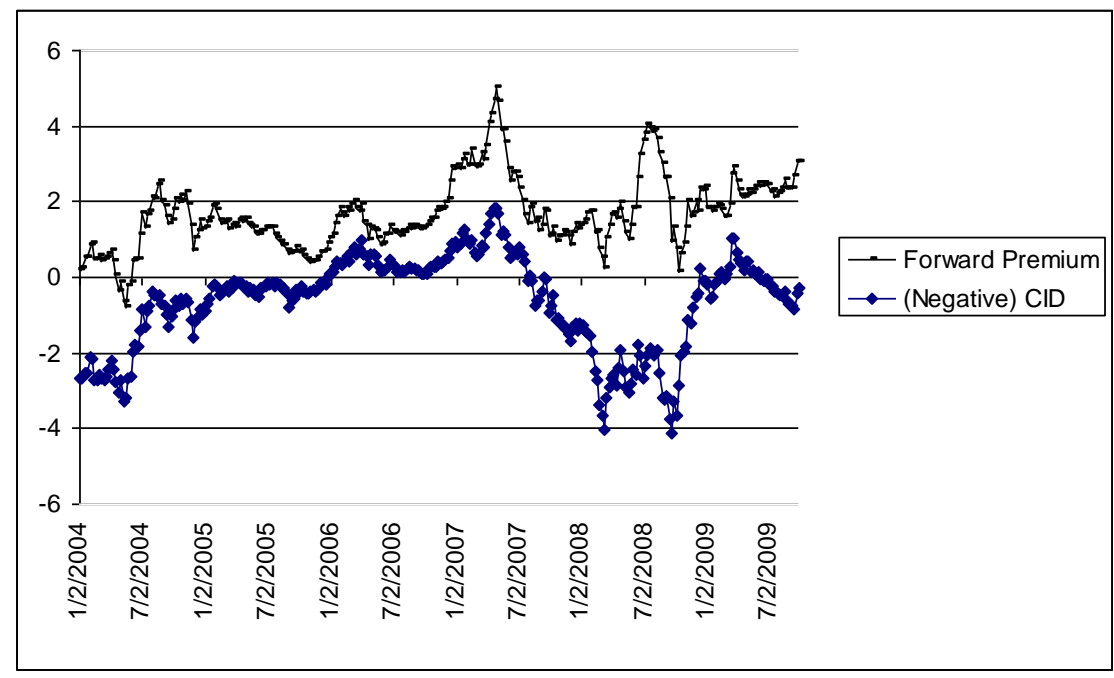

Figure 2: The Forward Premium and (Negative) CID (in per cent) 
A question of interest is whether the CID is stationary, and more generally, whether there is cointegration between Mifor and the Mibor swap rate. Table 2a provides results based on the Augmented Dickey-Fuller (ADF) methodology. Tests were carried out with the null of a unit root against the alternative of stationarity around a constant mean as well as the null of a unit root with trend against the alternative of trend stationarity or stationarity around a deterministic trend. The results in Table 2a support stationarity of the forward premium, but not of Mibor or Mifor. Also found to be nonstationary is the CID, a result that is supported by the apparent lack of cointegration between Mibor and Mifor documented in Table $2 \mathrm{~b}$ which presents results based on the Johansen methodology (Johansen, 1988, 1991, 1994 and Johansen and Julius, 1990) carried out using the software package, EasyReg International (Bierens, 2010).

Table 2a: Augmented Dickey Fuller (ADF) Unit Root Tests

\begin{tabular}{|l|c|c|c|c|}
\hline \multirow{2}{*}{ Variable } & \multicolumn{2}{c|}{ Null: Unit Root } & \multicolumn{2}{c|}{ Null: Unit Root with Trend } \\
\cline { 2 - 5 } & Test statistic & p-value & Test statistic & p-value \\
\hline Mifor & -2.2284 & 0.20 & -1.9744 & 0.61 \\
\hline Mibor & -1.9100 & 0.33 & -1.7158 & 0.74 \\
\hline Forward Premium & -3.1232 & 0.03 & -3.5484 & 0.03 \\
\hline CID & -2.2145 & 0.20 & -2.1812 & 0.50 \\
\hline First Difference in CID & -3.7078 & 0.00 & -3.8132 & 0.02 \\
\hline
\end{tabular}

Table 2b: Johansen Tests for Cointegration between Mibor and Mifor

\begin{tabular}{|c|c|c|c|c|c|c|c|c|}
\hline \multirow[b]{2}{*}{ Hypotheses } & \multicolumn{4}{|c|}{ Model - Intercepts only } & \multicolumn{4}{|c|}{ Model - Intercepts and Trends } \\
\hline & $\begin{array}{c}\text { Test } \\
\text { statistic }\end{array}$ & $\begin{array}{c}20 \% \\
\text { Critical } \\
\text { Value }\end{array}$ & $\begin{array}{c}10 \% \\
\text { Critical } \\
\text { Value }\end{array}$ & $\begin{array}{c}5 \% \\
\text { Critical } \\
\text { Value }\end{array}$ & $\begin{array}{c}\text { Test } \\
\text { statistic }\end{array}$ & $\begin{array}{c}20 \% \\
\text { Critical } \\
\text { Value }\end{array}$ & $\begin{array}{c}10 \% \\
\text { Critical } \\
\text { Value }\end{array}$ & $\begin{array}{c}5 \% \\
\text { Critical } \\
\text { Value }\end{array}$ \\
\hline Max Test & & & & & & & & \\
\hline $0 \mathrm{CV}$ s vs $1 \mathrm{CV}$ & 6.2 & 10.1 & 12.1 & 14.0 & 5.8 & 12.4 & 14.6 & 16.7 \\
\hline Trace Test & & & & & & & & \\
\hline At most $1 \mathrm{CV}$ & 2.8 & 1.7 & 2.8 & 4.0 & 2.0 & 1.7 & 2.7 & 3.8 \\
\hline At most $0 \mathrm{CV}$ & 8.9 & 11.2 & 13.3 & 15.2 & 7.8 & 13.4 & 15.7 & 18.1 \\
\hline
\end{tabular}

Note: The Max Test tests the null hypothesis of $r$ cointegrating vectors (CVs) against the alternative of $r+l \mathrm{CVs}$.

The Trace Test tests the null hypothesis that there are at most $r$ CVs against the alternative that there are more than $r$ CVs.

\section{The Blanchard-Quah Decomposition}

The non-stationary nature of the CID implies that the CID is affected by two types of shocks, permanent and temporary. As mentioned before, the permanent shock presumably arises from changes in risk, risk aversion and capital restrictions; and the temporary shock reflects a temporary disequilibrium.

This brings up the question of the relative importance of the permanent as compared to the temporary component of the CID. As is well known, there is no unique decomposition possible in a univariate framework (Enders, 2010). However, Blanchard and Quah (1989), henceforth referred to as BQ, offer a bivariate structural VAR framework to overcome this problem and accomplish a meaningful decomposition.

The following exposition of the BQ methodology closely follows Enders (2010). Suppose that the joint dynamics of two variables, $y_{t}$ and $z_{t}$ is described by the following Bivariate Moving Average (BMA) representation:

$$
\left[\begin{array}{c}
\Delta y_{t} \\
z_{t}
\end{array}\right]=\left[\begin{array}{ll}
C_{11}(L) & C_{12}(L) \\
C_{21}(L) & C_{22}(L)
\end{array}\right]\left[\begin{array}{l}
\varepsilon_{1 t} \\
\varepsilon_{2 t}
\end{array}\right]
$$

Above, $y_{t}$ is an $\mathrm{I}(1)$ variable and $z_{t}$ is an $\mathrm{I}(0)$ variable, and both variables are driven by two independent sources of white-noise innovation, $\varepsilon_{1}$ and $\varepsilon_{2}$. It may be assumed without loss of generality that the variancecovariance matrix of the innovations is the $2 \times 2$ identity matrix. The $C_{i j}(L)$ are polynomials in the lag operator with the coefficients measuring the impulse-responses of the $j^{\prime}$ th shock on the $i$ 'th variable: 


$$
C_{i j}(L) \varepsilon_{j, t}=c_{i j}(0) \varepsilon_{j, t}+c_{i j}(1) \varepsilon_{j, t-1}+c_{i j}(2) \varepsilon_{j, t-2}+\ldots
$$

Let $\varepsilon_{l}$ represent the "permanent" shock (i.e., the shock that has a permanent impact on $y_{t}$ ) and $\varepsilon_{2}$ represent the "temporary" shock (i.e., the shock that has only a temporary impact on $y_{t}$ ). Of course, $z_{t}$ being a stationary variable, both shocks can only have a temporary impact on it. The restriction implied by this condition on the VAR model is that the coefficients of the lag polynomial $C_{12}(L)$ must satisfy

$$
\sum_{k=0}^{\infty} c_{12}(k)=0
$$

The objective is to estimate the coefficients of the lagged polynomial. This is accomplished by first estimating the following bivariate, reduced-form VAR:

$$
\left[\begin{array}{c}
\Delta y_{t} \\
z_{t}
\end{array}\right]=\left[\begin{array}{ll}
A_{11}(L) & A_{12}(L) \\
A_{21}(L) & A_{22}(L)
\end{array}\right]\left[\begin{array}{c}
\Delta y_{t-1} \\
z_{t-1}
\end{array}\right]+\left[\begin{array}{c}
e_{1 t} \\
e_{2 t}
\end{array}\right]
$$

Above, the $A_{i j}(L)$ represent polynomials in the lag operator with the coefficients denoted by $a_{i j}(k)$, and $e_{1}$ and $e_{2}$ are error terms. The relationship between the innovations in the structural model $\left(\varepsilon_{1}\right.$ and $\left.\varepsilon_{2}\right)$, and the error terms in the reduced form model $\left(e_{1}\right.$ and $\left.e_{2}\right)$ is given by

$$
\left[\begin{array}{l}
e_{1 t} \\
e_{2 t}
\end{array}\right]=\left[\begin{array}{ll}
c_{11}(0) & c_{12}(0) \\
c_{21}(0) & c_{22}(0)
\end{array}\right]\left[\begin{array}{l}
\varepsilon_{1 t} \\
\varepsilon_{2 t}
\end{array}\right]
$$

Once the residuals of the reduced form model have been estimated using standard VAR methodology, the structural model shocks can be inferred from the equation above provided one has estimates of the $c_{i j}(0)$ terms above. The econometric task is to recover the parameters of the structural model (namely, the $C_{i j}(L)$ ) from those of the reduced form model (namely, the $A_{i j}(L)$ ). It may be noted that for a general structural model such as the one given by the BMA representation, this may not be possible. However, in this case, the condition that one of the two types of shocks has only a temporary impact on $y_{t}$ serves as an identifying restriction. As shown by Enders (2010), the equations used in identifying the $c_{i j}(0)$ terms are given by:

$$
\begin{aligned}
& \operatorname{var}\left(e_{1}\right)=\left(c_{11}(0)\right)^{2}+\left(c_{12}(0)\right)^{2} \\
& \operatorname{var}\left(e_{2}\right)=\left(c_{21}(0)\right)^{2}+\left(c_{22}(0)\right)^{2} \\
& \operatorname{Cov}\left(e_{1}, e_{2}\right)=c_{11}(0) c_{21}(0)+c_{12}(0) c_{22}(0) \\
& \left(1-\sum_{k=0}^{\infty} a_{22}(k)\right) c_{12}(0)+\sum_{k=0}^{\infty} a_{12}(k) c_{22}(0)=0
\end{aligned}
$$

Above, the first three equations are direct consequences of the relationship between the reduced form and structural form error terms. The last equation can be derived using the condition that $\varepsilon_{2}$ has only a temporary impact on $y_{t}$. The four equations above exactly identify the four $c_{i j}(0)$ terms.

In the context of this study, $y_{t}$ is the CID, $z_{t}$ is the forward premium, $\varepsilon_{l}$ is the permanent shock and $\varepsilon_{2}$ is the temporary shock. The first step in the BQ decomposition methodology (as mentioned previously) is to estimate a bivariate, reduced-form VAR for the two variables, CID and the forward premium. The lag-length is chosen to be 4 
periods based on the Akaike Information Criterion (AIC). The Ljung-Box tests support the white-noise nature of the residuals. The four equations above are used to back out the $c_{i j}(0)$, the coefficients that link the structural form shocks to the reduced form residuals. These estimated coefficients are then used to simulate the impact of structural shocks on the CID and the forward premium. Figures $3 \mathrm{a}$ and $3 \mathrm{~b}$ show the impulse response functions for a 24 -week horizon. The horizontal axis measures the number of weeks after a one-time shock, and the vertical axis plots the response of the variables in per cent per annum.
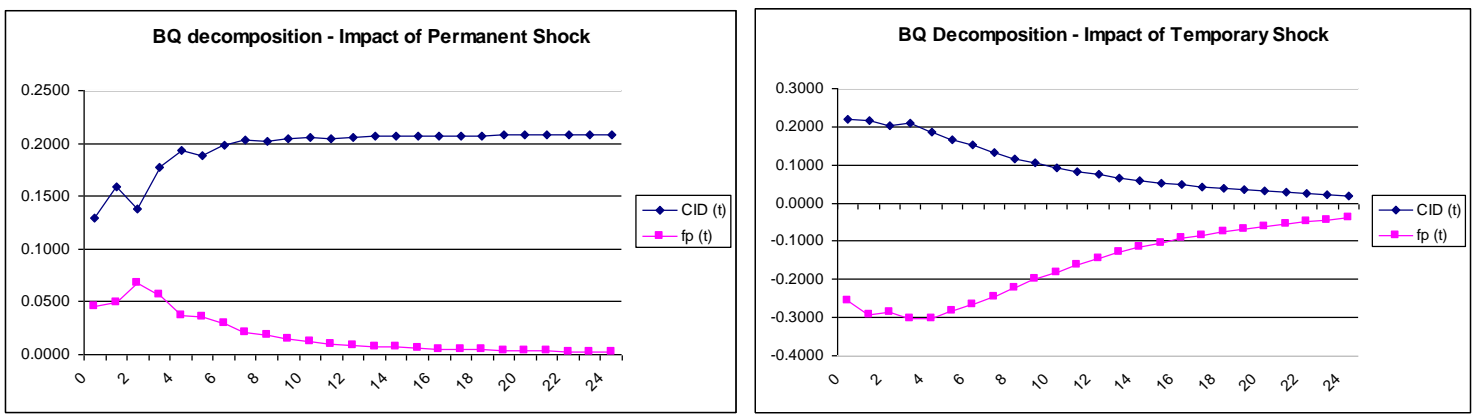

Panel 1: Impact of a Permanent Shock

Figure 3: Impulse-Response Functions:

Panel 2: Impact of a Temporary Shock on the CID and the Forward Premium (fp) on the CID and the Forward Premium (fp)

Panel 1 of Figure 3 shows the response of each variable to a one-time, one standard deviation permanent shock. As may be seen, such a shock results in a substantial and immediate increase of the CID. The bulk of the impact is felt in the initial few weeks, and the response is mostly complete within 8 weeks. On the forward premium, the impact of the shock is much smaller but non-zero. Interpreting the shock as an increase in risk premium, it appears to cause a short-term widening of the forward premium, perhaps due to a temporary increase in arbitrage activity. However, the forward premium reverts almost completely to its original level within 16 weeks, which is in keeping with its stationary nature.

Panel 2 shows the response of each variable to a temporary shock. As seen in the graph, the temporary shock causes an immediate decline in the forward premium and a simultaneous increase in the CID. The shock initially affects both the forward premium and the CID by roughly the same amount in absolute value. A one standard deviation temporary shock causes the forward premium to initially narrow by about 25 basis points (bps) and the CID to initially widen by about $22 \mathrm{bps}$. An interesting question is whether CIP deviations due to temporary shocks can be attributed to transactions costs. Prior studies (set in developed countries) estimate transactions costs related to covered interest arbitrage at around 10 bps per annum (see Frenkel and Levich, 1981, Clinton, 1988, and Balke and Wohar, 1997). Assuming that transactions costs for the dollar-rupee covered interest arbitrage are comparable, the impact on the CID of a one standard deviation temporary shock is large enough to suggest that such shocks would often push the CID outside the "neutral band" defined with respect to transactions costs; however, further analysis is needed to make more precise statements. Next, consider the speed with which the CID recovers from a temporary shock. Based on the impulse-response pattern, the "half-life" of the CID's reversion rate is about 9 weeks. At this time, the CID is about 11 bps higher than what it was before the shock. Most of the impact on the CID is reversed out within a few months, in keeping with the temporary nature of the shock; but it takes about 24 weeks to get to within 2 bps of the pre-shock level. Such a slow pace of recovery of the CID (in conjunction with the magnitude of the response of the CID to a one standard deviation temporary shock) suggests impediments to arbitrage. On the other hand, the rate at which the CID reverts to its pre-shock level is faster than that of the forward premium, at least in the initial periods. For example, in the tenth week after the shock, the CID is within 10 bps of the pre-shock level while the forward premium is still over 18 bps away. This suggests that capital restrictions, though present, are not totally binding.

Table 3 contains information about the relative importance of the two types of shocks in explaining the forecast error variance of each of the two variables. 
Table 3: Variance Decomposition

\begin{tabular}{|l|c|c|c|c|}
\hline \multirow{2}{*}{$\begin{array}{c}\text { Forecasting Horizon } \\
\text { (Weeks) }\end{array}$} & $\begin{array}{c}\text { Percent of Forecast Error Variance due to } \\
\left.\text { Permanent Shock } \mathbf{(}_{\mathbf{1}}\right)\end{array}$ & $\begin{array}{c}\text { Percent of Forecast Error Variance due to } \\
\text { Temporary Shock }\left(\boldsymbol{\varepsilon}_{\mathbf{2}}\right)\end{array}$ \\
\cline { 2 - 5 } & Forward Premium & CID & Forward Premium \\
\hline $\mathbf{1}$ & $26 \%$ & $3 \%$ & $74 \%$ & $97 \%$ \\
\hline $\mathbf{2}$ & $27 \%$ & $3 \%$ & $73 \%$ & $97 \%$ \\
\hline $\mathbf{3}$ & $27 \%$ & $4 \%$ & $73 \%$ & $96 \%$ \\
\hline $\mathbf{6}$ & $29 \%$ & $3 \%$ & $71 \%$ & $97 \%$ \\
\hline $\mathbf{1 2}$ & $28 \%$ & $2 \%$ & $72 \%$ & $98 \%$ \\
\hline $\mathbf{2 4}$ & $28 \%$ & $2 \%$ & $72 \%$ & $98 \%$ \\
\hline
\end{tabular}

It is interesting to note that permanent shocks explain only about $26 \%$ of the forecast error variability in the CID at short horizons and about $28 \%$ at longer horizons. The bulk of the variation in both variables is accounted for by temporary shocks. It is worth reiterating that the stationarity of the forward premium indicates that a permanent change in the risk premium is neither caused by, nor does it have any permanent impact on, the forward premium. In addition, the variance decomposition results show that the permanent shock explains less than $5 \%$ of the forecast error variability of the forward premium even at short horizons. This implies that covered interest arbitrage activity has a relatively limited influence on the forward premium even in the short run.

\section{CONCLUSION}

The focus of this study is on modeling and explaining the one-year Covered Interest Differential (CID) between the Indian and the US markets. The non-stationarity of the CID implies that the CID is affected by two types of shocks, permanent and temporary. The permanent shock presumably arises from changes in risk, risk aversion and capital restrictions. The temporary shock to the CID arises from changes in the forward premium without an immediate offsetting adjustment of the interest rate differential, or changes in the interest rate differential without an immediate offsetting adjustment of the forward premium. Thus the temporary shock reflects temporary disequilibrium. The study makes use of a bivariate Vector Autoregression (VAR) framework to model the joint dynamics of the (first difference of the) CID and the forward premium, and employs the Blanchard-Quah decomposition methodology in order to separate the effects of these two types of shocks and assess their relative importance.

The results suggest that permanent shocks have a substantial and immediate impact on the CID. However, such shocks explain less than $30 \%$ of the CID's forecast error variability at both short and long horizons. Thus, much less than half the variability of the CID is related to permanent changes in the risk premium. Further, permanent shocks explain less than 5\% of the forecast error variability of the forward premium at all horizons. The bulk of the variation in both variables is accounted for by temporary shocks. This suggests that expected exchange rate movements and hedging activity play a more important role than covered interest arbitrage activity in the determination of the forward premium. It is interesting that the temporary shock initially affects both the forward premium and the CID by roughly the same amount. This suggests that the temporary shock captured by this BQ methodology reflects transient volatility in the forward premium.

The size of the impact on the CID of a one standard deviation temporary shock suggests that it is unlikely that all or even most temporary CIP deviations can be explained away by transactions costs. Pursuing this question is left for future research. Further, once a temporary shock occurs, it takes the CID over 24 weeks to recover from it. These results suggest considerable impediments to arbitrage; however, the fact that, after a temporary shock, the CID reverts to its pre-shock level at a slightly faster rate than the forward premium, especially in the initial weeks, suggests that capital restrictions are not completely binding.

In conclusion, the study proposes a different approach to testing covered interest parity on a risk-adjusted basis, in the sense that the methodology allows for a country risk premium. However, it is important to note the limitations of the bivariate methodology used in the study. The main shortcoming is that it only allows identification of two types of shocks. However, each of these types of shocks may arise from more than one source. For example, a permanent shock to the CID may arise from a change in either risk or risk aversion or capital restrictions. The 
methodology is not capable of separating these different kinds of shocks. Similarly, there are multiple sources of temporary shocks to the CID, such as changes in exchange rate expectations, level of hedging or arbitrage activity, and inflation expectations. The potential problem is that the response of the variables (namely the CID and the forward premium) to each of these kinds of shocks may be different, which the methodology does not allow for. Extending the analysis to distinguish between these different kinds of shocks is left for future research.

\section{AUTHOR INFORMATION}

Vadhindran K. Rao is currently an Associate Professor of Finance at Metropolitan State University in Minneapolis. He has over 9 years of university experience as a faculty member as well as over 8 years of industry experience in software and banking. He has worked in areas such as financial software development/implementation and market risk management. His research interests include International Finance, Financial Markets and Risk Management.

E-mail: Vadhindran.Rao@Metrostate.edu.

\section{REFERENCES}

1. Balke, N. S., \& Wohar, M. E. (1997). Nonlinear Dynamics and Covered Interest Rate Parity (Working Paper 97-01, Federal Reserve Bank of Dallas).

2. Batten, J. A., \& Szilagyi, P. G. (2006). Arbitrage, Covered Interest Parity and Long-Term Dependence between the US Dollar and the Yen (The Institute for International Integration Studies Discussion Paper Series, IIIS Discussion Paper No. 128).

3. Bhatt, V., \& Virmani, A. (2005). Global Integration of India's Money Market: Interest Rate Parity in India (Indian Council for Research on International Economic Relations Working Paper No. 164).

4. Bierens, H. J. (2010). "EasyReg International", Department of Economics, Pennsylvania State University http://econ.la.psu.edu/ hbierens/EASYREG.HTM.

5. Bhoi, B. K., \& Dhall, S. C. (1998). Integration of Financial Markets in India: An Empirical Evaluation. RBI Occasional Papers, 19(4), 345-380.

6. Buigut, S., \& Rao, V. (2011). International Financial Integration of the Indian Money Market. International Journal of Economics and Finance, 3(4), 170-180.

7. Blanchard, O. J., \& Quah, D. (1989). The Dynamic Effects of Aggregate Demand and Supply Disturbances. American Economic Review, 79, 655-673.

8. Clinton, K. (1988). Transactions Costs and Covered Interest Arbitrage: Theory and Evidence. Journal of Political Economy, 96(2), 358-370.

9. $\quad$ Enders, W. (2010). Applied Econometric Time Series (3rd ed.). New Jersey: John Wiley.

10. Frenkel, J. A., \& Levich, R. M. (1975). Covered Interest Arbitrage: Unexploited Profits? Journal of Political Economy, 83(2), 325-338.

11. Frenkel, J. A., \& Levich, R. M. (1981). Covered Interest Arbitrage in the 1970's. Economics Letters, 8(3), 267-274.

12. Frankel, J. A. (1991). Quantifying International Capital Mobility in the 1980's' (NBER Working Paper No. 2856).

13. George, P., \& Mallik, D. (2009a). Monetary Policy and International Financial Integration - The Case Of India. The Curie Journal, BITS, Pilani.

14. George, P., \& Mallik, D. (2009b). Covered Interest Parity and International Financial Integration: The Case of India. The ICFAI Journal of Applied Finance, 15(2), 58-74.

15. Hutchison, M., Kendall, J., Pasricha, G., \& Singh, N. (2009). Indian Capital Control Liberalization: Evidence from the NDF Markets (National Institute of Public Finance and Policy, New Delhi, Working Paper No. 2009-60).

16. Jain, S., \& Bhanumurthy, N. R. (2005). Financial Markets Integration in India. Asia-Pacific Development Journal, 12(2), 15-32.

17. Johansen, S. (1988). Statistical analysis of cointegration vectors. Journal of Economic Dynamics and Control, 12(2-3), 231-254.

18. Johansen, S. (1991). Estimation and hypothesis testing of cointegration vectors in gaussian autoregressive models. Econometrica, 59, 1551-1580. 
19. Johansen, S. (1994). The Role of the Constant and Linear Terms in Cointegration Analysis of Nonstationary Variables. Econometric Reviews, 13(2), 205-229.

20. Johansen, S., \& Juselius, K. (1990). Maximum Likelihood Estimation and Inference on Cointegration with Applications to the Demand for Money. Oxford Bulletin of Economics and Statistics, 52(2), 169-210.

21. Mishra, A. K., \& Sebastian, V. J., \& Ramanathan, A. (2001). Test of Covered Interest Parity between U.S. Dollar \& Indian Rupee. The Indian Journal of Economics, 82(324).

22. Obstfeld, M., \& Taylor, A. M. (2004). Global Capital Markets: Integration, Crises and Growth. Cambridge, UK: Cambridge University Press.

23. Popper, H. (1993). Long-Term Covered Interest Parity - Evidence from Currency Swaps. Journal of International Money and Finance, 12(4), 439-448.

24. Prasad, E. S. (2009). India's Approach to Capital Account Liberalization (Discussion Paper No. 3927, The Institute for the Study of Labor (IZA), Bonn).

25. Sarno, L., \& Taylor, M. P. (2002). The Economics of Exchange Rates. Cambridge, England and New York: Cambridge University Press.

26. Sharma, A. K., \& Mitra, A. (2006). What Drives Forward Premia in Indian Forex Market? Reserve Bank of India Occasional Papers, 27(1 and 2).

27. Takezawa, N. (1995). Currency Swaps and Long-term Covered Interest Parity. Economics Letters, 49(2), 181-185.

28. Taylor, M. P. (1987). Covered Interest Parity: A High-Frequency, High-Quality Data Study. Economica, 54(216), 429-38.

29. Varma, J. R. (1997). Indian Money Market: Market Structure, Covered Parity and Term Structure. The ICFAI Journal of Applied Finance, 3(2), 1-10. 